\title{
Sumada al tratamiento abortivo estándar, la dexametasona parenteral previene la recurrencia de la migraña severa
}

Adding parenteral dexamethasone to standard abortive treatment prevents recurrence of acute severe migraine headache

Objetivo

Evaluar la efectividad de los corticoides parenterales para el alivio de la migraña severa y para prevenir su recurrencia.

\section{Fuente y selección de datos}

Búsqueda en bases de datos electrónicas (Cochrane Central Register of Controlled Trials, Medline, Embase, LILACS, CINAHL) y manual (conferencias de congresos de de neurología, cefalea y emergentología, guías de práctica clínica, contacto con companías farmacéuticas, con los autores de los estudios identificados y con expertos en cefalea). La búsqueda se limitó a ensayos clínicos controlados y aleatorizados que hubieran incluido adultos con migraña severa definida con criterios explícitos para diferenciarla de otros tipos de cefalea. Los de la rama "tratamiento" debían haber sido asignados a "corticoides parenterales más terapia abortiva estándar"; y los de la rama control, a "placebo más tratamiento abortivo estándar".

\section{Resultados principales}

Fueron incluidos siete estudios realizados entre 1999 y 2008 , con un total de 738 pacientes, llevados a cabo en departamentos de emergencia o clínicas de cefalea.

Evaluaron dosis parenterales de dexametasona (intravenosa o intramuscular) de 10 a $24 \mathrm{mg}$. El resultado primario medido fue la recurrencia de migraña entre las 24 y las 72 horas de instaurado el tratamiento agudo y los secundarios, la reducción del dolor luego del tratamiento agudo medido con una escala visual analógica y los efectos adversos del tratamiento.
El tratamiento con dexametasona se asoció con una reducción significativa en las tasas de recurrencia (RR 0,74; IC95\% 0,60 a 0,90; RRR 26\%; RRA 10,34\%) estimándose la necesidad de tratar nueve pacientes (IC95\% 6 a 25) para prevenir una recurrencia adicional. No se observaron diferencias significativas en la reducción inicial del dolor ni en los efectos adversos. Ver tabla 1.

Tabla 1: recurrencia de la migraña según la rama asignada (dexametasona o placebo sumados al tratamiento abortivo estándar)

\begin{tabular}{c|c|c|c|c|c|c} 
Resultado & $\begin{array}{c}\text { Dexametasona } \\
\mathbf{n = 3 8 5}\end{array}$ & $\begin{array}{c}\text { Control } \\
\mathbf{n = 3 5 3}\end{array}$ & $\begin{array}{c}\text { RR } \\
(\text { IC65\%) }\end{array}$ & RRR & RRA & $\begin{array}{c}\text { NWT } \\
\text { (IC95\%) }\end{array}$ \\
$\begin{array}{c}\text { Recurrencia de la } \\
\text { migraña dentro de } \\
\text { las } \mathbf{7 2} \text { horas }\end{array}$ & $29 \%$ & $39 \%$ & $\begin{array}{c}0.74 \\
(0,6 \text { a } 0,9)\end{array}$ & $26 \%$ & $10,34 \%$ & $\begin{array}{c}9 \\
\text { (6 a 25) }\end{array}$ \\
\hline
\end{tabular}

RR: riesgo relativo. RRR: reducción del riesgo relativo. RRA: reducción de riesgo absoluto. NNT: número necesario de tratar.

\section{Conclusiones}

Sumada a la terapia abortiva estándar, la dexametasona se asoció a una reducción significativa en la recurrencia de migraña dentro de las 72 horas de instaurado el tratamiento agudo.

Palabras clave: migraña, dexametasona, ensayo clinico aleatorizado.

Key words: migraine, dexametasone, randomised controlled trial.

Fuente de financiamiento: Gobierno Canadiense; Canadian Association of Emergency Physicians Research Consortium.

\section{Comentario}

La migraña es un problema de salud común entre los adultos, con una prevalencia de $6 \%$ en hombres y $15 \%$ en mujeres ${ }^{1}$. Representa el $5 \%$ de las consultas a los departamentos de emergencia ${ }^{2}$ y es una causa mayor de discapacidad asociada a altas tasas de ausentismo laboral. La recurrencia de migraña durante las primeras 24 a 72 horas posteriores al episodio agudo afecta al $49 \%$ de los pacientes.

Las guías de tratamiento de la cefalea, proponen a los anti inflamatorios no esteroides (AINE) por vía oral oral (ibuprofeno, naproxeno, ácido tolfenámico, diclofenac y ketorolac) como primera línea para la migraña leve a moderada, o en aquellos pacientes con migraña severa, que tienen en antecedente de haber respondido bien a estos agentes en episodios previos. El tratamiento específico de la migraña con triptanos y dihidoergotamina fue propuesto como abordaje inicial de elección para aquellos pacientes con migraña moderada a severa, o en quienes la cefalea leve a moderada responde pobremente a Ios AINE. Por otro, lado, la asociación con antieméticos como la metoclopramida se aconseja en la migraña que se acompaña de náuseas o vómitos. Vale aclarar que hasta la publicación de este trabajo, las guías de tratamiento de la cefalea ${ }^{3}$ reservaban a la dexametasona como tratamiento de segunda línea o para el rescate de pacientes cuya migraña no había cedido con el tratamiento abortivo estándar.

\section{Conclusiones de la comentadora}

El estudio de Colman y col. que hoy comentamos provee buena evidencia para recomendar la utilización de la dexametasona junto con la terapia abortiva estándar como tratamiento de primera línea del ataque agudo de migraña con el objetivo de disminuir la recurrencia, haya o no cedido el dolor. Si bien el estudio no midió el efecto a largo plazo de los corticoides, existe amplia experiencia de que su monodosis no representa mayores riesgos.

Catalina Brosens [ Servicio de Medicina Familiar y Comunitaria del Hospital Italiano de Buenos Aires. catalina.brosens@hospitalitaliano.org.ar ]

Brosens C. Sumada al tratamiento abortivo estándar, la dexametasona parenteral disminuye el riesgo de recurrencia de la migraña severa. Evid. actual. práct. ambul; 11(5): 137, Sep-oct. 2008. Comentado de: Colman I y col. Parenteral dexamethasone for acute severe migraine headache: metaanalysis of randomised controlled trials for preventing recurrence. BMJ 2008;336:1359-1361. PMID:18541610. Disponible en URL: http://www.bmj.com/cgi/reprint_abr/336/7657/1359.pdf (último acceso 22/09/08).

\section{Referencia}

1. Stewart W y col. Migraine prevalence. A review of population-based studies. Neurology 1994; 44:S17-23

2. Vinson D. Treatment patterns of isolated benign headache in US emergency departments. Ann Emerg Med 2002; 39: 215-22.

3. US Headache Consortium; Evidence-Based Guidelines for Migraine Headache in the Primary Care Setting: Pharmacological Management of Acute Attacks; 2000. 